\title{
Factors influencing prioritization for carpal tunnel syndrome consultation
}

\author{
Bryan Chung MD PhD, Steven F Morris MD MSc
}

B Chung, SF Morris. Factors influencing prioritization for carpal tunnel syndrome consultation. Can J Plast Surg 2013;21(1):33-36.

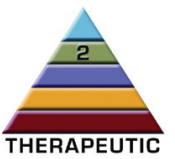

BACKGROUND: In a socialized medicine model, prioritization of referrals for specialist consultation is highly important in the distribution of heath care. For high-burden diseases, such as carpal tunnel syndrome (CTS), the factors that influence prioritization are not well understood.

OBJECTIVE: To determine the factors that influence the prioritization of referrals for CTS consultation by plastic surgeons in Canada.

METHODS: All members of the Canadian Society of Plastic Surgery with e-mail addresses were invited to participate in an online survey regarding the method by which they prioritize referrals for CTS.

RESULTS: Forty per cent of invited members completed the survey (150 surgeons). Of these, 118 (79\%) stated that they performed CTS surgery. The majority of respondents who performed CTS surgery prioritized their consultation list chronologically (77\%). Factors that would alter the chronological order or prioritization included subsequent contact by the referring physician (24\%); personal relationship with the patient $(16 \%)$; and specific information in the referral letter (15\%), which usually involved symptom severity or electromyography findings. Sixty-six per cent of plastic surgeons stated that there was no conscious decision on how they came to choose the method of prioritization they used for referrals regarding CTS.

DISCUSSION: The majority of plastic surgeons in Canada prioritize referrals for consultation on CTS chronologically. A minority of respondents reported reassigning priority based on clinical severity. The rationale for the methods by which Canadian Society of Plastic Surgery members prioritize these referrals is poorly understood. Further study on developing evidence-based prioritization methods may be useful in assisting surgeons and their patients in outcome-based decisions.

Key Words: Carpal tunnel syndrome; Consultation; Prioritization; Referrals

$\mathrm{T}$ he burden of illness of carpal tunnel syndrome (CTS) is high. It is the most common upper extremity disorder in Workers' Compensation Board (WCB) claims. Median time off from work has been estimated to be 93 days, resulting in costs in excess of $\$ 13$ million dollars per year in 1996 in Ontario (WCB cases only) (1).

In many medical systems in the world, referral to a specialist for surgical intervention by a physician (usually primary care) is often the route by which patients gain access to consultation with a surgeon. Several studies have examined the process by which primary care physicians can improve successful referral rates (2-6), including a Cochrane review on improving outpatient referrals from primary to secondary care professionals (7). However, the literature is lacking in studies that examine how specialist care professionals decide the priority in which patients referred for the same or similar problems are seen for consultation.

Anecdotally, surgeons tend to see patients for consultation in the order that referrals arrive. Some factors that may affect the order in which patients who have the same reason for referral include the following: primary care physician advocacy (ie, the family physician may call the surgeon to advocate or provide additional information); a personal relationship with the patient either directly, or by proxy (eg, a friend of a family member); professional relationship with a

\author{
Les facteurs influant sur la priorisation des \\ consultations à cause d'un syndrome du canal carpien
}

HISTORIQUE : Dans un modèle de médecine sociale, la priorisation des aiguillages vers une consultation en spécialité revêt une grande importance dans la distribution des soins. Dans le cas des maladies au taux de morbidité élevé, telles que le syndrome du canal carpien (SCC), les facteurs qui influent sur la priorisation sont mal compris.

OBJECTIF : Déterminer les facteurs qui influent sur la priorisation des aiguillages en vue d'une consultation relative à un SCC auprès des chirurgiens plasticiens du Canada.

MÉTHODOLOGIE : Tous les membres de la Société canadienne des chirurgiens plasticiens qui ont fourni une adresse de courriel ont été invités à participer à un sondage virtuel sur la méthode qu'ils utilisent pour prioriser les aiguillages en vue d'un SCC.

RÉSULTATS : Quarante pour cent des membres invités ont rempli le sondage (150 chirurgiens). De ce nombre, 118 (79\%) ont déclaré avoir exécuté des chirurgies du SCC. La majorité des répondants qui avaient exécuté de telles chirurgies priorisaient leur liste de consultation de manière chronologique (77 \%). Les facteurs qui pouvaient modifier l'ordre chronologique ou la priorisation incluaient un contact subséquent par le médecin traitant (24\%), une relation personnelle avec le patient (16\%) et de l'information précise dans la lettre d'aiguillage (15\%), laquelle précisait généralement la gravité des symptômes ou les résultats de l'électromyographie. Quarante-deux pour cent des chirurgiens plasticiens ont déclaré qu'il n'y avait aucun processus de décision conscient dans le choix de leur méthode de priorisation.

EXPOSÉ : La majorité des chirurgiens plasticiens du Canada priorise de manière chronologique les aiguillages en consultation à cause d'un SCC. Une minorité de répondants déclare réévaluer les priorités compte tenu de la gravité clinique. On comprend mal le motif de la méthode par laquelle les membres de la Société canadienne des chirurgiens plasticiens priorisent ces aiguillages. D'autres études sur l'élaboration de méthodes de priorisation fondées sur des données probantes pourraient être utiles pour aider les chirurgiens et leurs patients à prendre des décisions fondées sur les issues.

group of individuals (eg, team surgeon for a sports team); and financial/system-wide incentive or initiatives (eg, WCB or thirdparty payers such as the Royal Canadian Mounted Police for CTS surgery).

In a study of ear, nose and throat (ENT) surgeons in the United Kingdom, both primary care physicians and ENT surgeons were asked to rate a set of 50 referral letters as 'urgent', 'soon' and 'routine'. There was a marked difference between primary care physicians and ENT surgeons in terms of prioritization rating. Of the 17 letters that were rated urgent by the primary care physician, the ENT surgeon agreed with the urgent rating in only six (8).

A study on prioritization of ophthalmology referral letters by nurse practitioners, optometrists and senior house officers also exhibited only moderate agreement with respect to priority rating (9).

Although the disparity in prioritization rating is apparent from these two studies, no additional studies examining the basis on which prioritization ratings are made, particularly in the case of consultation for CTS, have been conducted.

The objectives of the present study were to determine the methods by which plastic surgeons in Canada prioritize referrals for CTS surgery consultation, and to determine the self-reported basis on which these methods are based.

Department of Surgery, Dalhousie Univeristy, Halifax, Nova Scotia

Correspondence: Dr Steven F Morris, 4443-1796 Summer Street, Halifax, Nova Scotia B3H 3A7. Telephone 902-473-7054,

fax902-473-8773, e-mail sfmorris@dal.ca 


\author{
1. Do you perform carpal tunnel surgery? \\ - Yes \\ - No [Respondents were thanked for the time and survey was completed] \\ 2. Where is your practice located? \\ - BC \\ - Alberta \\ - New Brunswick \\ - Saskatchewan \\ Nova Scotia \\ - Manitoba \\ - Ontario \\ - Quebec \\ 3. What is the nature of your practice? \\ - Tertiary care centre (all specialties locally available) \\ - Secondary care centre (not all specialties locally available) \\ - Primary care (limited local access to other specialties) \\ 4. What type of location is your practice located? \\ - Metropolitan (population $>100,000$ ) \\ - City (population $>40,000$ ) \\ - Rural (population $\leq 40,000$ )
}

5. How long have you been in practice in plastic surgery? (post-residency)

6. When prioritizing referrals for consultation for carpal tunnel syndrome, do you generally see patients in the order in which referrals arrive?

- Yes (Respondents were directed to question 6B)

- No (Respondents were directed to question 6C)

6B: If you generally see patients in the order in which their referrals arrive, what factors would alter the otherwise chronological ordering of carpal tunnel syndrome consultations in terms of seeing a patient more urgently? (Check all that apply)

- Referring physician contacting you by phone or e-mail

- Presence of EMG results in referral

- WCB case

- Information in the referral letter (eg, specific symptoms) (Please specifiy)

- Frequent requests for an appointment by the patient

- Personal relationship to the patient (eg, a friend/relative; a friend/relative of relative or colleague)

- Professional association to patient (eg, team surgeon for a sport team)

- Third party payer

- Other (please specify):

6C: If you do not generally see patients for consultation for carpal tunnel syndrome in the order in which you receive their referrals, please describe the method by which you prioritize the order in which you see these patients?

7. What factors other than chronological order would delay a patient's consultation for carpal tunnel syndrome?

8. How did you decide on the method by which you prioritize consultations for carpal tunnel syndrome?

- No conscious decision on prioritization

- Based on the practice of other plastic surgeons or physicians

- Based on a study or studies (Please specifiy studies if possible)

- Other (please describe):

Figure 1) Survey to assess factors influencing prioritization for carpal tunnel consultations among Canadian plastic surgeons. (Adapted from online version). EMG Electromyography; WCB Workers' Compensation Board

\section{METHODS}

The present study was based on a cross-sectional survey. E-mail addresses of Canadian plastic surgeons were obtained from the member directory of the Canadian Society of Plastic Surgery. An e-mail was sent to each member inviting them to participate in the study, with a link to an electronic survey (Figure 1). A reminder e-mail was sent two weeks after the first invitation. Further contact was not performed unless solicited.

\section{Analysis}

The survey consisted of both open- and closed-ended elements. Closed-ended elements were tabulated and reported using descriptive statistics. Themes from open-ended elements were extracted from responses and grouped with similar themes to create data that were then tabulated.

\section{RESULTS}

A total of 150 members responded to the survey (40\% response rate). Of these, $118(79 \%)$ of respondents stated they performed CTS surgery.

Demographic data of the respondents are summarized in Table 1. The median duration of practice was 15 years (interquartile range six to 25 years, range one to 40 years), with a skew toward surgeons with $<15$ years in practice.

The majority $(77 \%)$ of respondents who perform CTS surgery stated they prioritized their consultation list chronologically. Of these surgeons, the top three factors that would alter the chronological order in which patients were prioritized were:

1. Subsequent contact by the referring physician.

2. A personal relationship with the patient.

3. Specific information in the referral letter, which most commonly commented about symptom severity or muscle atrophy in the thenar area.

Table 2 reports the complete list of factors that were reported to alter the chronological order in which patients were normally prioritized. Table 3 summarizes specific information used to alter prioritization of a referral among surgeons who reported that they saw referrals in chronological order.

Of the respondents who reported that they did not prioritize referrals in chronological order (23\%), 'severity of disease' was a prevalent theme among described factors on which prioritization was based. Table 4 reports the complete list of factors that affect the order of prioritization among surgeons who did not see referrals in chronological order. Other factors that were reported to be associated with delay of consultation are shown in Table 5.

Sixty-six per cent of plastic surgeons stated that there was no conscious decision on how they came to choose the method of prioritization they used for referrals regarding CTS (Table 6).

\section{DISCUSSION}

The present article reports the results of a survey of approximately $40 \%$ of all Canadian plastic surgeons on prioritization practices for CTS consultation. Our results suggest that a high proportion of Canadian plastic surgeons perform CTS surgery and that the majority prioritize their referrals chronologically. There is, however, a substantial proportion of surgeons who prioritize received referrals according to other criteria, such as 'disease severity', which was not uniformly defined from surgeon to surgeon. It is also noteworthy that among surgeons who see patients chronologically, several factors were identified in which the priority of the patient was changed. Approximately one-half of these surgeons responded that subsequent contact by the referring physician caused them to alter the chronological priority of their referral queue, indicating a strong role for physician advocacy for their patients, particularly in the setting of changing clinical status.

There is, however, a lack of evidence for which these prioritization methods are based. Only three surgeons responded that their choice of prioritization method was based on a study, but none cited any literature specifically. The majority of surgeons reported no conscious decisionmaking process on how they prioritize referrals for CTS consultation, suggesting a haphazard or heuristic evolution of a system that 'works'. To date, there have been no studies that have evaluated the benefit of one method over another in terms of patient outcomes and/or reduction of morbidity as a result of increased or decreased wait times. 
TABLE 1

Demographics of participating surgeons who perform carpal tunnel syndrome surgery

\begin{tabular}{lc}
\hline Location of practice & $28(25)$ \\
British Columbia & $9(8)$ \\
Alberta & $3(3)$ \\
Saskatchewan & $4(4)$ \\
Manitoba & $37(33)$ \\
Ontario & $7(6)$ \\
Quebec & $5(4)$ \\
New Brunswick & $8(7)$ \\
Nova Scotia & $1(1)$ \\
Prince Edward Island & $0(0)$ \\
Newfoundland and Labrador & $10(9)$ \\
Other & \\
Type of practice & $83(74)$ \\
Tertiary care (all specialties locally available) & $27(24)$ \\
Secondary care (not all specialties locally available) & $2(13)$ \\
Primary care (limited local access) & \\
Practice environment & $93(83)$ \\
Metropolitan (population $>100,000)$ & $15(13)$ \\
City (population $>40,000)$ & $4(4)$ \\
Rural (population $\leq 40,000)$ & \\
\hline
\end{tabular}

Data presented as $n(\%)$

TABLE 2

Factors affecting prioritization among surgeons who see referrals in chronological order

\begin{tabular}{lc}
\hline Factor & Responses, $\mathbf{n}$ \\
\hline Subsequent contact from referring physician & 57 \\
Personal relationship to patient (eg, friend/relative) & 39 \\
Professional association to patient & 24 \\
Presence of electromyography/nerve conduction studies & 21 \\
Workers' Compensation Board case & 17 \\
Frequent requests for an appointment by patient & 14 \\
Patients always seen in order & 14 \\
Third-party payer & 9 \\
Other & 8 \\
\hline
\end{tabular}

Possible limitations of the present study were the low response rate and the skew of respondents toward surgeons with $<15$ years of clinical practice. While ascertaining responder bias was not possible, there does not appear to be any evidence that these results are not generalizable to the larger population of plastic surgeons in Canada. In terms of the skew of respondents toward those with fewer years in practice, this bias may be beneficial in that the prioritization methods reported are likely to continue into the coming decades as these respondents' practices continue to mature. Responses from surgeons whose practices are closer to retirement could be considered less useful for future planning because their contribution to overall trends will have less of an enduring effect.

Given the low percentage of respondents (28\%) who reported that they would reassign priority of a referral based on the inclusion of indicators of higher 'severity of disease' in the original referral letter, timeliness of referral may be the overarching factor in determining wait times to consultation for CTS in the majority of plastic surgery practices in Canada. However, $74 \%$ of respondents who reported a predominant chronological prioritization process also reported that additional patient advocacy in the form of subsequent contact by the referring physician would alter their priority rating.

Wait times for surgery include two waiting periods: the time from the initial referral to the time of first consultation; and the time from the decision for surgery to the actual operating date. There is evidence
TABLE 3

Specified information sought within referral letters that would alter chronological order of consultations

\begin{tabular}{lc}
\hline Factor & Responses, $\mathbf{n}(\mathbf{n}=\mathbf{2 5})$ \\
\hline Severity of symptoms & 11 \\
Mention of muscle atrophy & 8 \\
Mention of constant numbness & 4 \\
Acute symptoms & 1 \\
Work interference & 1 \\
\hline
\end{tabular}

TABLE 4

Factors affecting prioritization among surgeons who do not see referrals in chronological order

\begin{tabular}{lc}
\hline Factor & Responses, $\mathbf{n}(\mathbf{n}=\mathbf{2 7})$ \\
\hline Severity as defined by electromyography/nerve & 19 \\
$\quad$ conduction studies & 10 \\
Severity of symptoms & 5 \\
Mention of muscle atrophy & 4 \\
Mention of constant numbness & 4 \\
Subsequent contact from referring physician & 2 \\
Work interference & 1 \\
Acute symptoms &
\end{tabular}

\section{TABLE 5}

\section{Other factors associated with delay of consultation}

\begin{tabular}{lc}
\hline Factor & Responses, $\mathbf{n}$ \\
\hline Patient delay (eg, missed appointment) & 22 \\
No electromyography/nerve conduction results in referral & 11 \\
Mild symptoms & 8 \\
\hline
\end{tabular}

TABLE 6

Rationale for method of prioritization

\begin{tabular}{lc}
\hline Rationale & Responses ( $\mathbf{n}=\mathbf{1 1 0})$ \\
\hline No conscious decision & $73(66)$ \\
Based on practice of other plastic surgeons & $18(16)$ \\
Based on a study or studies (none specified) & $3(2)$ \\
Other & $16(15)$ \\
Personal experience & $14(13)$ \\
Reimbursement & $1(0.9)$ \\
Experience on operating room committee & $1(0.9)$ \\
\hline
\end{tabular}

Data presented as $n$ (\%)

to suggest that patients with shorter duration of symptoms experience better outcomes than those with longer duration of symptoms $(10,11)$. However, debate remains as to identifying patients at highest risk of permanent disability (12). Decreasing wait times to surgery will involve both shortening not only the time from the decision to perform surgery to the date of surgery, but also the interval between initial referral to surgical consultation. Development of evidence-based prioritization rules will play a large role not only in the distribution of health care but also in minimizing long-term or permanent disability.

\section{REFERENCES}

1. Manktelow RT, Binhammer P, Tomat LR, Bril V, Szalai JP.

Carpal tunnel syndrome: Cross-sectional and outcome study in Ontario workers. J Hand Surg Am 2004;29:307-17.

2. Patrick G, Bisgaier J, Hasham I, Navarra T, Hickner J. Specialty care referral patterns for the underserved: A study of community health centers on the South side of Chicago. J Health Care Poor Underserved 2011;22:1302-14.

3. Perumal D, Niederer R, Raynel S, McGhee CN. Patterns of ophthalmic referral and emergency presentations to an acute tertiary eye service in New Zealand. N Z Med J 2011;124:35-47. 


\section{Chung and Morris}

4. Barnett ML, Keating NL, Christakis NA, O’Malley AJ, Landon BE. Reasons for choice of referral physician among primary care and specialist physicians. J Gen Intern Med 2012;27:506-12.

5. Antoszewski B, Kardas P, Kasielska A, Fijalkowska M. Family physicians' perception of plastic surgery and its influence on referral. A survey from Poland. Eur J Gen Pract 2012;18:22-5.

6. McBride D, Hardoon S, Walters K, Gilmour S, Raine R. Explaining variation in referral from primary to secondary care: Cohort study. BMJ 2010;341:c6267.

7. Akbari A, Mayhew A, Al-Alawi MA, et al. Interventions to improve outpatient referrals from primary to secondary care. Cochrane Database of Syst Rev 2008;(4):CD005471.

8. Pothier DD, Repanos C. Referral letters: Are we prioritizing consistently? J Laryngol Otol 2005;119:377-80.
9. Hodi S. Management of ophthalmology referral letters in the United Kingdom: Are traditional methods the best? Ophthalmic Physiol Opt 2007;27:394-8.

10. Eskandari MM, Ozge A, Oztuna V, Colak M, Kanik A, Kuyurtar F. Effect of patient age and symptom duration on subjective and objective outcomes of carpal tunnel surgery. Orthopedics 2005;28:600-2.

11. Tay LB, Urkude R, Verma KK. Clinical profile, electrodiagnosis and outcome in patients with carpal tunnel syndrome: A Singapore perspective. Singapore Med J 2006;47:1049-52.

12. Turner A, Kimble F, Gulyas K, Ball J. Can the outcome of open carpal tunnel release be predicted?: A review of the literature. ANZ J Surg 2010;80:50-4. 